\title{
Risk for onset of health conditions among community-living adults with spinal cord and traumatic brain injuries
}

Suzanne McDermott, Robert Moran, Tan Platt, Terri Isaac, Hope Wood and Srikanth Dasari Department of Family and Preventive Medicine, University of South Carolina School of Medicine, Columbia, South Carolina, USA

\begin{abstract}
This research describes the onset of 13 health conditions and death among 38 adults with spinal cord injuries (SCls) and 149 adults with traumatic brain injuries (TBIs) compared to adults without disabilities in the same primary care setting, using a retrospective cohort design. The subjects were accrued from an urban and a rural practice, both affiliated with a university family medicine department. Survival analyses, using Cox proportional hazard models, were used to model the onset of each of the health conditions. The results indicated adults with $\mathrm{SCl}$ had an increased risk for onset of chronic obstructive pulmonary disease and depression. Individuals with TBIs had an increased risk for onset of anxiety, chronic obstructive pulmonary disease, dementia, depression, and seizures. Neither group had increased risk for asthma, cancer, coronary artery disease, congestive heart failure, diabetes, hypertension, obesity, or transient ischaemic attack. The only conditions with increased risk were those previously identified as secondary to traumatic injury. The other conditions including death did not have higher incidence among the study group, during 7-9 years of retrospective follow-up.
\end{abstract}

Key words: hazard ratios; secondary health conditions; spinal cord injury; traumatic brain injury

Received: November 2005; accepted: July 2006

\section{Introduction}

Traumatic brain injury (TBI) and spinal cord injury (SCI) are leading causes of death and disability in young adults (Charlifue et al., 1999; Thurman et al., 1999). Survival has improved for both of these conditions, resulting in an increased interest in the longterm health outcomes for survivors (Pentland et al., 1995; Hibbard et al., 1998; Middleton et al., 2004). The literature on long-term outcomes for people with disabilities resulting from trauma, includes a number of cross-sectional studies and a few longitudinal studies focusing on social, economic, and selfreported health outcomes (Dikmen et al., 2003;

Address for correspondence: Suzanne McDermott, Department of Family and Preventive Medicine, University of South Carolina School of Medicine, 3209 Colonial Drive, Columbia, SC 29208, USA.Email: suzanne.mcdermott@palmettohealth.org

(C) 2007 Cambridge University Press
Colantonio et al., 2004). There are numerous reports of patients with TBI having long-term activity limitations, respiratory conditions, vision problems, and approximately half report memory and other neurological impairments (Ashley et al., 1997; Hammond et al., 2001). In addition, there are numerous reports in the literature about re-hospitalization following TBI and SCI (Cifu et al., 1999; Marwitz et al., 2001).

In recent years, there has been a focus on the health of people with disabilities, with particular attention to promoting healthy behaviour and preventing onset of secondary conditions. A secondary condition is defined as any condition to which a person with a primary diagnosis is more susceptible and may include medical, physical, emotional, family, or community problems (Lollar et al., 2001). Most reports of secondary conditions are based on crosssectional data collected through surveys and single time record reviews. This makes it impossible to determine the cause-effect relationships. We used 
prior reports from the literature, combined with our knowledge of adult primary care problems, to select the conditions we studied. We focused on several secondary conditions for SCI and TBI, namely anxiety, chronic obstructive pulmonary disease, dementia, depression, and seizure. We also selected a group of conditions that have high incidence in the general population but do not result in permanent disability. Thus for example, we selected transient ischaemic attack, instead of stroke since the later condition often results in a permanent disability. The common adult health conditions selected for study were asthma, cancer, coronary artery disease, congestive heart failure, diabetes, hypertension, obesity, and transient ischaemic attack. Finally we looked at incidence of death during the study period for both groups.

There are no published reports on the long-term health experience of adults with SCI or TBI compared to adults with no disability when all groups are recruited from primary care settings instead of from rehabilitation outpatient or hospital settings. Thus, based on our review of the literature two hypotheses were tested in this study:

1) There is significantly higher incidence of secondary medical conditions (anxiety, chronic obstructive pulmonary disease, dementia, depression, and seizure) in patients with TBI or SCI, compared to patients without disabilities.

2) There are no differences in incidence of selected common health conditions (asthma, cancer, coronary artery disease, congestive heart failure, diabetes, hypertension, obesity, and transient ischaemic attack) and death between patients with TBI, SCI, and those with no disability.

\section{Methods}

A retrospective cohort design was used, to study development of health conditions among adults receiving primary care in either a large urban family practice centre or a small rural practice. Case and comparison patients were selected from a pool of over 58000 patients at one of the practices during the study period (1990-2003). There were 51146 records at the urban site and 7851 records at the rural site. The two practice sites include a population made up of $58 \%$ women, $35 \%$ African-American, 2\% Latino, and 3\% Asian.
The study was approved by the Institutional Review Board for a medical record review using both computerized medical records and the companion paper records archived from earlier medical care. The paper records were brought out of storage and read by the coders. Coding was done according to study protocols that applied to both computerized and paper records. Thus, some patient medical records spanned over 30 years.

\section{Case definitions}

The case definition of SCI and TBI used in this study was finding the diagnosis in physician progress notes and/or problem lists. The ICD-9 code for SCI was 952. For TBI the ICD9 codes were 800, 801, 803, 804, 851-854 (World Health Organisation, 2000).

The study subjects were established patients in one of the two primary care practices with comprehensive medical records including consultation notes from the other specialists who provided care. The completeness of the SCI was not always in the primary care record although the cord level of injury was available. The injury severity score from the initial hospitalization for the TBI was usually in the medical record but often did not reflect the degree of disability when the patient entered primary care. Therefore the severity of the injury at the time the individual entered one of the two practices was determined by the primary care physician based on the following classification:

\begin{tabular}{|c|c|c|c|}
\hline & Mild & Moderate & Severe \\
\hline $\begin{array}{l}\text { SCI (ICD9: } \\
952)\end{array}$ & Not used & Paraplegia & Tetraplegia \\
\hline $\begin{array}{l}\text { TBI (ICD9: } \\
800,801 \\
803,804 \\
851-854)\end{array}$ & $\begin{array}{l}\text { Blurred } \\
\text { vision, } \\
\text { attention } \\
\text { problems, } \\
\text { personality } \\
\text { change, or } \\
\text { headaches }\end{array}$ & $\begin{array}{l}\text { Seizures, } \\
\text { double vision, } \\
\text { decreased } \\
\text { balance, } \\
\text { equipment } \\
\text { required for } \\
\text { mobility, or } \\
\text { major mental } \\
\text { illness }\end{array}$ & $\begin{array}{l}\text { No instrumental } \\
\text { ADLs, required } \\
\text { caregiving, or } \\
\text { wheelchair use }\end{array}$ \\
\hline
\end{tabular}

The case definition for secondary conditions was diagnosis, by a physician with accompanying diagnostic tests and ICD9 code, for anxiety, chronic obstructive pulmonary disease, dementia, depression, and seizure.

Primary Health Care Research and Development 2007; 8: 36-43 
The case definition for common health conditions was diagnosis, by a physician with accompanying diagnostic tests and ICD9 code for asthma, cancer, coronary artery disease, congestive heart failure, diabetes, hypertension, obesity, or transient ischaemic attack. Death was defined by finding a participant in the death file from the National Death Registry.

\section{Study participants}

Cases were identified by a computerized search of the electronic medical record from 1990 to 2003. The search terms included SCI, TBI, head injury, and the associated ICD9 codes. During the study period, all patients with a TBI or an SCI entered the practice after their injury from a variety of sources including the Level 3 trauma unit in the hospital which operated the urban practice, the proximal private rehabilitation hospital, and area physicians.

Comparison patients were selected from the pool of patients receiving health care in the same two practices, after ruling out the presence of any disability. We excluded patients with sensory deficits (deaf, blind), neurological conditions (stroke, adult attention deficit hyperactivity disorder), developmental disabilities (autism, cerebral palsy, mental retardation), and psychiatric disabilities (schizophrenia, bipolar disorder), from the pool from which patients without disabilities were selected. We then stratified patients into 10-year increments based on age at entry into the practices so the cases and comparison group would be approximately the same age and have similar follow-up time. Finally patients with less than three visits to the practice were excluded from both the case and the comparison group. The mean number of visits for the comparison group was 18 (range 3-166) for those with TBI it was 29 (range 3-166) and for SCI it was 25 (range 3-74). These procedures resulted in 1842 comparison individuals.

\section{Data collection and analysis}

Data were collected by two medical record abstracters, under the regular supervision of the study physician, who was also the medical director of the urban practice. Inter-rater reliability was monitored through duplication of record abstraction by the abstractors. Whenever there was a discrepancy in coding, the issue was reviewed at our weekly staff meeting. All discrepancies in coding were mediated by the study epidemiologist and physician, and other cases that would be impacted by the discrepancy were re-analysed.

All data were analysed using the SAS statistical package (SAS Institute, 1999). Comparison of demographic variables between the comparison group and each of the trauma groups were conducted using $t$-tests for continuous variables and $\chi^{2}$ tests for categorical variables. We compared patients with mild TBI to those with moderate/severe levels of TBI to justify the inclusion of the mild category in the analysis (Table 2). Survival analysis was used to model the onset of each of the conditions in the patients with SCI, TBI, and those without disability. Only patients without each of the secondary or selected condition diagnoses when they entered the practice were included in the survival analysis, so onset could be observed. Thus, patients with TBI and seizures when they entered the practice were excluded from the analysis of onset of seizures. Cox proportional hazards model was used since it is a semi-parametric model for explaining the effects of covariates on survival times. In order to arrive at reliable estimates of the three major functions (survival, probability density, and hazard) and their standard errors at each time interval the minimum recommended sample is 30 and this was available for both the SCI and the TBI groups (Feller, 1972). The survival time of each member of a population is assumed to follow its own hazard function, $h_{i}(t)$, $h_{i}(t)=h\left(t ; z_{i}\right)=h_{0}(t) \exp \left(z_{i}^{\prime} \beta\right)$ where $h_{0}(t)$ is an arbitrary and unspecified baseline hazard function, $z_{i}$ is the vector of measured explanatory variables for the $i$ th individual, and $\beta$ is the vector of unknown regression parameters associated with the explanatory variables. The Cox model was used to determine if there was a statistically significant difference between the onset of each condition, in patients with SCI or TBI compared to the group without disabilities, after controlling for age, race, gender, practice location (urban/rural), and injury severity.

\section{Results}

Table 1 presents the characteristics of the patients with SCI, TBI, and no disability who were included in the study. The mean starting age for care in the two family medicine practices was 35-41 years and the mean number of years of follow-up in the 
Table 1 Characteristics of patients with $\mathrm{SCl}, \mathrm{TBI}$, and comparison patients

\begin{tabular}{|c|c|c|c|c|c|}
\hline Characteristic & $\begin{array}{l}\text { Comparison group } \\
(n=1842)\end{array}$ & $\begin{array}{l}\text { SCl group } \\
(n=38)\end{array}$ & $\begin{array}{l}P \text {-value versus } \\
\text { controls }\end{array}$ & $\begin{array}{l}\text { TBI group } \\
(n=149)\end{array}$ & $\begin{array}{l}P \text {-value versus } \\
\text { controls }\end{array}$ \\
\hline $\begin{array}{l}\text { Starting age for medical } \\
\text { records (mean and } \\
\text { standard deviation) }\end{array}$ & $\begin{array}{l}39.5 \text { years } \\
(11.7)\end{array}$ & $\begin{array}{l}35.0 \text { years } \\
(12.2)\end{array}$ & 0.0249 & $\begin{array}{l}40.8 \text { years } \\
(14.8)\end{array}$ & 0.1971 \\
\hline $\begin{array}{l}\text { Follow-up years (mean } \\
\text { and standard deviation) }\end{array}$ & $\begin{array}{l}7.0 \text { years } \\
(6.4)\end{array}$ & $\begin{array}{l}9.4 \text { years } \\
(6.5)\end{array}$ & 0.0168 & $\begin{array}{l}9.2 \text { years } \\
(7.5)\end{array}$ & $<0.0001$ \\
\hline Race (\% African-American $)^{\mathrm{b}}$ & 53.5 & 55.3 & 0.8269 & 53.0 & 0.9149 \\
\hline Died $(\%)^{b}$ & 6.8 & 7.9 & 0.2520 & 7.4 & 0.0615 \\
\hline $\begin{array}{l}\text { Severity of primary disability } \\
\text { - Mild } \\
\text { - Moderate } \\
\text { - Severe }\end{array}$ & $\begin{array}{l}\mathrm{n} / \mathrm{a} \\
\mathrm{n} / \mathrm{a} \\
\mathrm{n} / \mathrm{a}\end{array}$ & $\begin{array}{l}\#(\%) \\
0.0 \\
14(36.8 \%) \\
24(63.2 \%)\end{array}$ & & $\begin{array}{l}\#(\%) \\
81(54.4 \%) \\
53(35.5 \%) \\
15(10.1 \%)\end{array}$ & \\
\hline
\end{tabular}

${ }^{\mathrm{a}}$ t-test

${ }^{b} \chi^{2}$ test

Table 2 Comparison of condition prevalence by severity of TBI

\begin{tabular}{lccc}
\hline Condition & $\begin{array}{l}\text { TBl mild \% with } \\
\text { condition } n=81\end{array}$ & $\begin{array}{l}\text { TBl moderate and severe } \\
\% \text { with condition } n=68\end{array}$ & $P$-value for $\chi^{2}$ test* \\
\hline Anxiety & 13.41 & 7.25 & 0.22 \\
Asthma & 4.88 & 2.90 & 0.54 \\
Cancer & 10.98 & 10.14 & 0.87 \\
Coronary artery disease & 15.85 & 7.25 & 0.10 \\
Congestive heart failure & 7.32 & 2.90 & 0.23 \\
Chronic obstructive pulmonary disease & 19.51 & 17.39 & 0.74 \\
Dementia & 18.29 & 18.84 & 0.93 \\
Depression & 39.02 & 36.23 & 0.72 \\
Diabetic & 18.29 & 13.04 & 0.38 \\
Hypertension & 46.34 & 36.23 & 0.21 \\
Obesity (ever) & 79.27 & 65.22 & 0.053 \\
Seizure & 19.51 & 50.72 & $<0.001$ \\
TIA & 1.22 & 4.35 & 0.23 \\
Death & 8.54 & 5.80 & 0.52 \\
\hline
\end{tabular}

*Testing difference in proportion with condition among those with moderate/severe TBI versus mild TBI

practices was 7 years for the comparison group and approximately 9 years for the patients with SCI and TBI. The number of female patients was higher in the comparison group than those with SCI or those with TBI. The three groups were approximately $50 \%$ African-American. Seven percent of patients from all three groups died during the follow-up period. Finally, the severity of the injury was substantially different for the two case groups. Of the individuals with SCI, most had a severe injury (tetraplegia) while among the individuals with TBI the severity was skewed in the opposite direction where a majority had a mild injury.
We compared the prevalence of each of the conditions for people with mild versus moderate and severe TBI (Table 2). The only significant prevalence difference was seizure disorder which was more than double in the patients with moderate and severe TBI compared to mild TBI.

We used hazard ratios to model the incidence of health conditions among the individuals with SCI and those with TBI, compared to comparison adults, after controlling for age, race, severity of injury, urban or rural clinic, and gender (Table 3). For individuals with SCI there was a statistically significant increased risk for onset of two of the secondary Primary Health Care Research and Development 2007; 8: 36-43 
Table 3 Adjusted* hazard ratio for health conditions controlling for the other conditions, for patients with SCl orTBI versus comparison patients

SCl: Hazard ratio

(95\% confidence interval)

(38 cases, 1842 controls)
TBI: Hazard ratio

(95\% confidence interval)

(149 cases, 1842 controls)

Common health conditions

Asthma

Cancer

Coronary artery disease

Congestive heart failure

Diabetes

Hypertension

Obesity

Transient ischaemic attack

Death

$2.03(0.28,14.66)$

$2.52(0.61,10.35)$

$* *$

$* *$

$1.63(0.40,6.59)$

$0.91(0.29,2.84)$

$0.88(0.39,1.96)$

$2.99(0.72,12.48)$

$1.35(0.50,3.63)$

$4.02(1.47,11.03)^{* * *}$

$3.15(1.72,5.77)^{* * *}$

$4.38(0.58,33.26)$
$0.68(0.28,1.66)$

$1.24(0.68,2.25)$

$1.06(0.51,2.21)$

$1.34(0.52,3.43)$

$1.19(0.70,2.02)$

$1.04(0.75,1.43)$

$1.08(0.85,1.37)$

$1.60(0.48,5.41)$

$1.58(0.78,3.19)$

$2.19(1.57,3.05)^{* * *}$

$1.63(1.03,2.59)^{* * *}$

$52.7(21.6,128.7)^{* * *}$

$1.72(1.26,2.35)^{* * *}$

$66.5(36.3-121.8)^{* * *}$

*Each model controlled for the other risk factors and conditions, age, race, gender, location of practice, and severity of $\mathrm{TBI}$ or $\mathrm{SCl}$

**No patients with $\mathrm{SCl}$ had these conditions during the time they were in the practice

***Statistically significant $P<0.05$

health conditions: chronic obstructive pulmonary disease and depression. Likewise, individuals with TBI were at statistically significant increased risk for chronic obstructive pulmonary disease and depression. Patients with TBI had twice the risk of anxiety compared to patients without disability. The adults with TBI also had an extremely high incidence of dementia and seizure. There was no statistically significant increase in the incidence of asthma, cancer, coronary artery disease, congestive heart failure, diabetes, hypertension, obesity, transient ischaemic attack, and death in patients with SCI or TBI compared to the other patients without disability.

Since the health conditions studied are common in all groups of the population, we were interested in determining if there was a statistically significant difference in the age of onset for each health condition, for patients with TBI or SCI and the comparison group. The results are shown in Table 4. Patients with TBI did have significantly earlier onset of dementia and seizures compared to patients without disability. They had statistically significantly later onset for coronary artery disease, chronic obstructive pulmonary disease, and depression. Those with SCI had significantly later onset of obesity. There was no statistically significant difference for any of the other conditions.

\section{Discussion}

The use of a large urban and a rural primary care medical practice to estimate incidence of disease allowed us to compare the onset rates between adults with SCI or TBI and a comparison group of patients without disabilities. One of the strengths of our approach was the mean retrospective follow-up period of 7-9 years per patient, so the progression to disease could be studied. In addition, we had ascertainment of some common conditions because of repeated contacts with the primary care physician. This might not be detected if a crosssectional approach had been used. This is important because our study group came from a community population, not from specialty or rehabilitation clinics, disability service providers, or persons living in institutions, who are often used in studies of patients with traumatic injuries.

One of the limitations of this study was the small number of patients with a SCI in the two practices. This was handled by using a procedure that requires 
Table 4 Age at onset of secondary conditions

\begin{tabular}{llll}
\hline Mean onset age of condition & $\begin{array}{l}\text { Mean onset } \\
\text { age of comparison }\end{array}$ & $\begin{array}{l}\text { Mean onset } \\
\text { age of SCI }\end{array}$ & $\begin{array}{l}\text { Mean onset } \\
\text { age ofTBI }\end{array}$ \\
\hline Anxiety & 44.8 & 40.8 & 43.0 \\
Asthma & 40.6 & 28.2 & 40.1 \\
Cancer & 53.9 & 52.8 & 43.6 \\
Coronary artery disease & 56.3 & 68.1 & $63.4^{*}$ \\
Congestive heart failure & 55.9 & 68.4 & 61.2 \\
Chronic obstructive pulmonary disease & 54.0 & 37.5 & $57.5^{*}$ \\
Dementia & 69.4 & 69.3 & $54.6^{*}$ \\
Depression & 42.8 & 31.7 & $46.0^{*}$ \\
Diabetes & 49.2 & 51.3 & 51.8 \\
Hypertension & 47.5 & 41.7 & 50.7 \\
Obesity & 41.2 & $44.5^{*}$ & 43.4 \\
Seizure & 40.3 & 37.0 & $39.7^{*}$ \\
Transient ischaemic attack & 58.9 & 68.1 & 56.2 \\
Death & 55.5 & 58.4 & 58.4 \\
\hline
\end{tabular}

*Significantly different from comparison group at $\alpha=0.05$

only 30 observations (Feller, 1972). A second problem was the bias toward mild severity for those with TBI. We examined the impact of TBI severity by comparing mild TBI to moderate and severe TBI and found seizures were the only condition that was statistically significantly more likely in the moderate and severe group (Table 2). This gave us confidence to include the mild cases in the survival analysis. We then used survival analyses to model the incidence of conditions since this procedure allows for disparate sample sizes and adjustment for confounders. In these analyses age, race, practice location (urban or rural), gender, and injury severity (mild, moderate, severe) were considered confounders. Finally, we expect the cases included in this analysis are not representative of all adults with SCI and TBI since ascertainment occurred in primary care practices. We expect patients who receive their care from specialists might have different experiences with secondary conditions.

An important contribution of this research is the result of using survival analysis. This technique allowed us to study the onset of disease, so we were able to identify early onset of seizures and dementia in patients with a TBI. Survival analysis is only used for patients who are disease-free at the beginning of the study period. Thus, we only included patients without seizures in the Cox Proportional Hazard Model to determine if onset was higher in the patients with TBI compared to the patients without disability. Our study identified an incidence rate for dementia that was over 66 times higher and 8 years earlier for patients with TBI.

A substantial proportion of research has relied on self-report or cross-sectional record review from a rehabilitation unit or a trauma centre, to determine the age of onset of health conditions, among survivors (Hammond et al., 2001; Dikmen et al., 2003; Breed et al., 2004; Colantonio et al., 2004). It is likely that patients followed by rehabilitation and trauma programmes are not representative of community survivors of SCI and TBI. In fact, they are likely to be the survivors with complex and severe secondary medical conditions.

Previously reported population based studies of adults with SCI and TBI have primarily focused on quality of life measures, functional independence, and disability ratings (Hammond et al., 2001; Dikmen et al., 2003; Franceschini et al., 2003; Zemper et al., 2003; Coantonio et al., 2004). The studies that focus on health conditions for adults with SCI have primarily researched the occurrence of acute secondary conditions such as pressure sores and urinary tract infections, and the chronic sequella of pain and spasticity (Vogel et al., 2002; Zemper et al., 2003; Forchheimer et al., 2004). Our study focused on a combination of expected sequella of trauma and some common health conditions in order to inform primary care providers about what to expect when they embark on the care of these patients during their adult lives. The differences between the two disability groups, adults with SCI 
and those with TBI, have implications for clinical practice; however it is noteworthy that the incidence rate of common medical conditions such as asthma, cancer, diabetes, hypertension, obesity, and transient ischaemic attack are no different for the two disability groups than for the comparison group.

Patients with SCI had higher incidence rates for two secondary conditions, chronic obstructive pulmonary disease and depression. This is consistent with the literature about the range of sequella of SCI including genitourinary and gastrointestinal problems, pressure sores, and respiratory problems (Pentland et al., 1995; Charlifue et al., 1999). Our study focused on onset of conditions and excluded acute infections and short-term problems while other studies included the frequently occurring bladder infections and skin breakdown. Patients with TBI had statistically significant higher incidence rates for anxiety, depression, chronic obstructive pulmonary disease, dementia, and seizure. This finding of higher incidence of both neurologic conditions and other system problems is consistent with other reports in the recent literature, including Breed,Flanagan and Watson (Breed et al.,2004) and Hibbard, Uysal, Sliwinski and Gordon (Hibbard et al., 1998) who have reported long-term health problems associated with TBI. Breed used selfreport of health problems to compare age-matched, community-dwelling individuals with and without TBI. Compared with those without TBI, older individuals with TBI reported more problems with endocrine/metabolic and neurologic symptoms, while younger adults with TBI reported more difficulty with sleep, with the odds of having a specific health condition changing in increments of approximately 5 years. Hibbard reported people with TBI were more likely to report symptoms related to not only their neurologic systems but also to their endocrine and genitourinary systems.

The main contribution of this study is that we show a difference in known secondary health conditions but no difference in common health conditions. The secondary contribution is the finding that dementia and seizures did occur at an earlier age for those with TBI and thus has implications for care and expense. Coronary artery disease, chronic obstructive pulmonary disease, and depression had later onset in those with TBI, and obesity had later onset in those with SCI. We believe the later onset for coronary artery disease and chronic objective pulmonary disease results from lower smoking rates Primary Health Care Research and Development 2007; 8: 36-43 in patients with TBI compared to our comparison group. In addition patients with both TBI and SCI have more frequent visits to the physician and this allows for more counselling time for lifestyle behaviours. This could result in the lower smoking rates and the consequences of coronary artery disease and chronic obstructive pulmonary disease for those with TBI and later onset of obesity in those with SCI. It is not clear why the TBI group would have later onset of depression. Additional research is needed to determine whether these results generalize to other settings. Nonetheless, this study should provide some guidance to primary care providers about expected incidence of conditions in adults with traumatic injuries.

\section{Practice implications}

These findings suggest that primary care physicians should be alert to higher rates of depression and chronic obstructive pulmonary disease in patients with SCIs. Likewise, they should anticipate adults with TBI are more likely to develop those two conditions as well as anxiety, dementia, and seizures.

\section{Acknowledgements}

This project was funded by the Centers for Disease Control (CDC) Health and Disability Grant R04/ CCR418776.

\section{References}

Ashley, M.J., Persel, C.S., Clark, M.C. and Krych, D.K. 1997: Long-term follow-up of post-acute traumatic brain injury rehabilitation: a statistical analysis to test for stability and predictability of outcome. Brain Injury 11, 677-90.

Breed, S.T., Flanagan, S.R. and Watson, K.R. 2004: The relationship between age and the self-report of health symptoms in persons with traumatic brain injury. Archives of Physical Medicine and Rehabilitation 85 (4 Suppl 2), S56-57.

Charlifue, S.W., Weitzenkamp, D.A. and Whiteneck, G.G. 1999: Longitudinal outcomes in spinal cord injury: aging, secondary conditions, and well-being. Archives of Physical Medicine and Rehabilitation 80, 1429-34.

Cifu, D.X., Kreutzer, J.S., Marwitz, J.H., Miller, M., Hsu, G.M., Seel, R.T., Englander, J., High Jr, W.M. and Zafonte, R. 1999: Etiology and incidence of rehospitalization after traumatic 
brain injury: a multicenter analysis. Archives of Physical Medicine and Rehabilitation 80, 85-90.

Colantonio, A., Ratcliff, G., Chase, S., Kelsey, S., Escobar, M. and Vernich, L. 2004: Long-term outcomes after moderate to severe traumatic brain injury. Disability and Rehabilitation 26, 253-61.

Dikmen, S.S., Machamer, J.E., Powell, J.M. and Temkin, N.R. 2003: Outcome 3 to 5 years after moderate to severe traumatic brain injury. Archives of Physical Medicine and Rehabilitation 84, 1449-57.

Feller, W. 1972: An introduction to probability theory and its applications, second edition, Volume II. New York: John Wiley \& Sons.

Forchheimer, M., McAweeney, M. and Tate, D.G. 2004: Use of the SF-36 among persons with spinal cord injury. American Journal of Physical Medicine and Rehabilitation 83, 390-95.

Franceschini, M., Di Clemente, B., Rampello, A., Nora, M. and Spizzichino, L. 2003: Longitudinal outcome 6 years after spinal cord injury. Spinal Cord 41, 280-85.

Hammond, F.M., Grattan, K.D., Sasser, H., Corrigan, J.D., Bushnik, T. and Zafonte, R.D. 2001: Long-term recovery course after traumatic brain injury: a comparison of the functional independence measure and disability rating scale. Journal of Head Trauma Rehabilitation 16, 318-29.

Hibbard, M.R., Uysal, S., Sliwinski, M. and Gordon, W.A. 1998: Undiagnosed health issues in individuals with traumatic brain injury living in the community. Journal of Head Trauma Rehabilitation 13, 47-57.

Lollar, D.J. 2001: Public health trends in disability. In Albrecht, G.L., Seelman, K.D. and Bury, M., editors,
Handbook of disability studies. California: Sage Publications, 754-71.

Middleton, J.W., Lim, K., Taylor, L., Soden, R. and Rutkowski, S. 2004: Patterns of morbidity and rehospitalisation following spinal cord injury. Spinal Cord 42, 359-67.

Marwitz, J.H., Cifu, D.X., Englander, J. and High, Jr, W.M. 2001: A multi-center analysis of rehospitalizations five years after brain surgery. Journal of Head Trauma Rehabilitation 16, 307-17.

Pentland, W., McColl, M.A. and Rosenthal, C. 1995: The effect of aging and duration of disability on long-term health outcomes following spinal cord injury. Paraplegia 33, 367-73.

SAS Institute. 1999: SAS/STAT user's guide, Version 8. Cary, NC: SAS Institute.

Thurman, D.J., Alverson, C.A., Dunn, K.A., Geurrero, J. and Sniezek, J.E. 1999: Traumatic brain injury in the United States: a public health perspective. Journal of Head Trauma Rehabilitation 46, 8-11.

Vogel, L.C., Krajci, K.A. and Anderson, C.J. 2002: Adults with pediatric-onset spinal cord injuries: part 3: impact of medical complications. Journal of Spinal Cord Medicine 25, 297-305.

World Health Organisation. 2000: International statistical classification of diseases, ninth edition. Geneva, Switzerland: Word Health Organisation.

Zemper, E.D., Tate, D.G., Roller, S., Forchheimer, M., Chiodo, A., Nelson, V.S. and Scelza, W. 2003: Assessment of a holistic wellness program for persons with spinal cord injury. American Journal of Physical Medicine and Rehabilitation $82,957-68$. 